\title{
ROLE OF URODYNAMIC TESTING IN THE EVALUATION OF PERSISTENT URINARY INCONTINENCE IN POSTMENOPAUSAL WOMEN
}

\author{
Garuda Lakshmi ${ }^{1}$, K. Suhasini2 ${ }^{2}$ Sarika H. Pandya ${ }^{3}$, Adipudi Ramya ${ }^{4}$, D. V. S. Ramakrishna Prasad 5 \\ ${ }^{1}$ Associate Professor, Department of Obstetrics \& Gynaecology, CKM, Warangal. \\ ${ }^{2}$ Associate Professor, Department of Obstetrics \& Gynaecology, CKM, Warangal. \\ ${ }^{3}$ Consultant Urologist at Hyderabad Nursing Home. \\ ${ }^{4}$ Resident at Hyderabad Nursing Home. \\ 5I/c Professor, Urologist at Osmania Medical College.
}

\section{ABSTRACT}

\section{AIM}

To evaluate the importance of Urodynamic assessment in postmenopausal women for confirmation of the type of Incontinence, which is valuable in guiding the management by conservative or surgical measures.

\section{MATERIAL AND METHODS}

This is a multicentric prospective study conducted from Nov 2010 - May 2012 on 88 postmenopausal women who presented with complaints of Urinary Incontinence at Outpatient dept. of Tertiary Teaching Hospital, Govt. Maternity Hospital, Petlaburz, Hyderabad and at Hyderabad Nursing Home, Basheerbagh, Hyderabad. Out of 88 patients who were recruited and evaluated, 26 patients responded to initial management and the remaining 62 patients were enrolled for Urodynamic study but 3 patients deferred and lost for follow up. UDS was conducted in these 59 patients, cystoscopy was optional and essential in 5 cases and hence it was performed in these cases.

Methods and units of multichannel conventional UDS used in this study maintained the standards recommended by the international continence society. Filling, voiding cystometry and uroflowmetry was done.

\section{RESULTS}

The distribution of the patients in our study according to age, parity, BMI, Literacy and mode of delivery were analysed. The presence of precipitating factors (1 or more), associative with cystocele and history of prior surgeries were also recorded. In our study out of 59 patients, Detrusor underactivity (37.28\%) were seen in maximum number of patients followed by mixed incontinence $(25.42 \%)$ and $\mathrm{OAB}(18.64 \%)$. Clinical experience and the literature suggests that older women have decreased detrusor contractility, increase in $\mathrm{OAB}$ and mixed incontinence and decrease in pure stress symptoms. Our results support this statement. In our study UDS has completely changed the course of management in many cases and guided us to specific and appropriate treatment. Established voiding and continent centres have advised that these patients should thoroughly evaluated with UDS and their treatment should be individualized according to their symptoms with team approach.

\section{CONCLUSION}

Urodynamic study is gold standards in evaluation of urinary incontinence which guide us for specific management with better results. UDS provide enough information for treatment decision and prognosis in cases of UI. Research is critically needed to provide data that will allow better understanding of the unique nature of this urologic disease in these older postmenopausal women.

\section{KEYWORDS}

Urinary Incontinence (UI), Urodynamic Study (UDS), Quality of Life (QOL), Overactive Bladder (OAB, Body Mass Index (BMI).

HOW TO CITE THIS ARTICLE: Lakshmi G, Suhasini K, Pandya SH, et al. Role of Urodynamic Testing in the Evaluation of Persistent Urinary Incontinence in Postmenopausal Women. J Evolution Med Dent Sci 2016;5(3):177-184, DOI: 10.14260/jemds/2016/41

\section{INTRODUCTION}

Urinary incontinence is underdiagnosed and undertreated all over the world. It is a common distressing medical disorder that effects approximately $50 \%$ of women during their lifetime. It is associated with significant decrement in function and Quality of Life (QOL) of women.(1,2) Incontinence has a larger economic impact than many chronic conditions and diseases. $(3)$

\section{INCIDENCE}

The overall incidence all over the world in post-menopausal women was $30-40 \%$. A 3.5 million in UK, 13 million in USA suffer from urinary incontinence according to 2012 census.

Financial or Other, Competing Interest: None.

Submission 17-11-2015, Peer Review 18-11-2015,

Acceptance 02-12-2015, Published 08-01-2016.

Corresponding Author:

Dr. Garuda Lakshmi,

Flat No. 402, Prakruthi Dew Drops Apartment,

1-8-557/A/2, Adjacent to Bajaj Electronics,

RTC X roads, Chikkadpally,

Hyderabad-500020, Telangana State.

E-mail:garudalakshmi5@gmail.com,kambhamsuhasini@gmail.com DOI:10.14260/jemds/2015/41
It is three times more common in women than men. According to International Continence Society and American Urological Society the definition of urinary incontinence is "The complaint of any involuntary loss of urine that is a social or hygienic problem." $(4)$

Five types of incontinence (Abram et al., 2002, 2009b)

- Stress Urinary Incontinence.

- Urge Incontinence (OAB).

- Overflow Incontinence (Results from underactive detrusor muscle or bladder outlet obstruction).

(OSCEs) which can assess the student's all three domains cognitive, psycho-motor and affective.

The objective of this study was to assess the perception of the students and faculty members about Objective Structured Clinical Examinations (OSCEs) in General Medicine. Sandvik Severity Index Scoring System was used to characterize the degree of urinary incontinence taking into consideration both the amount and frequency as parameters. ${ }^{(5,6)}$ 


\begin{tabular}{|ccc|}
\hline SCORE & AMOUNT & FREQUENCY \\
1) & FEW DROPS/SMALL AMOUNT & MORE THAN MONTHLY \\
2) & MODERATE/LARGE AMOUNT & MONTHLY \\
3 ) & - & WEEKLY \\
4) & - & DAILY \\
\hline
\end{tabular}

\begin{tabular}{|c|c|}
\hline $\begin{array}{l}\text { Score is calculated by } \\
(1-8)\end{array}$ & $\begin{array}{c}=\text { AMOUNT X FREQUENCY } \\
(1-2) \times(1-4)\end{array}$ \\
\hline Grading by score & \\
\hline MILD & $1-2$ \\
\hline MODERATE & $3-4$ \\
\hline SEVERE & $6-8$ \\
\hline
\end{tabular}

This score is comparable with PAD weighing test: MEAN PAD WT (gm./24hrs).(7)

\begin{tabular}{|ll|}
\hline MILD & $:$ 2-14GMS \\
MODERATE & $:$ 15-30GMS \\
SEVERE & $:$ 31-65GMS \\
\hline
\end{tabular}

Urodynamics is "The dynamic study of the pressure flow relationship between the bladder and urethra for the purpose of defining functional status of the lower urinary tract."

The role of Urodynamics in clinical practice was explained by Hooker and Colleagues (2009).

1. To identify type of bladder dysfunction, overactive (Causing failure to store) or underactive (Causing failure to empty) or bladder outlet obstruction in incontinence women.

2. To predict the consequence of lower urinary tract dysfunction on the upper urinary tract.

3. To understand the reasons for failure of previous treatment.

4. To predict the outcome of treatment.

\section{Types of Urodynamics}

1. Conventional Multichannel UDS

2. Ambulatory UDS

3. Videourodynamics.

\section{Limitation of Conventional UDS are}

It is performed under unphysiologic circumstances in special laboratory. This strange and hostile environment may influence micturition or incontinence significantly. Ambulatory UDS is used to overcome these problems and is more physiological and is done through many natural filled void cycle.(8,9) Videourodynamic evaluation uses fluoroscopy with concurrent measurement of bladder and urethral pressure, which gives simultaneous evaluation of structure and function. It is a procedure of choice for documenting bladder neck dysfunction.

\section{ADVANTAGES OF VIDEOURODYNAMICS}

1. No need for EMG routinely.

2. Sphincter and bladder neck can be evaluated fluoroscopically throughout bladder filling and during stress maneuvers.

3. Is method of choice when diagnosis cannot be made on conventional UDS in evaluation of female incontinence.

4. Precisely diagnose intrinsic sphincter deficiency, urge incontinence and urethral hypermobility.

\section{DISADVANTAGES OF VIDEOURODYNAMICS}

1. Costly.

2. Not available at all centres.

3. Radiation due to usage of fluoroscopy.

\section{MATERIAL AND METHODS}

This is a multicentric prospective study conducted from Nov 2010 - May 2012 on 88 postmenopausal women who presented with complaints of Urinary Incontinence at Outpatient Dept. of Tertiary Teaching Hospital, Govt. Maternity Hospital, Petlaburz, Hyderabad and at Hyderabad Nursing Home, Basheerbagh Hyderabad. Out of 88 patients who were recruited and evaluated, 26 patients responded to initial management and the remaining 62 patients were enrolled for Urodynamic study but 3 patients deferred and lost for follow-up. UDS was conducted in these 59 patients, cystoscopy was optional and essential in 5 cases and hence it was performed in these case.

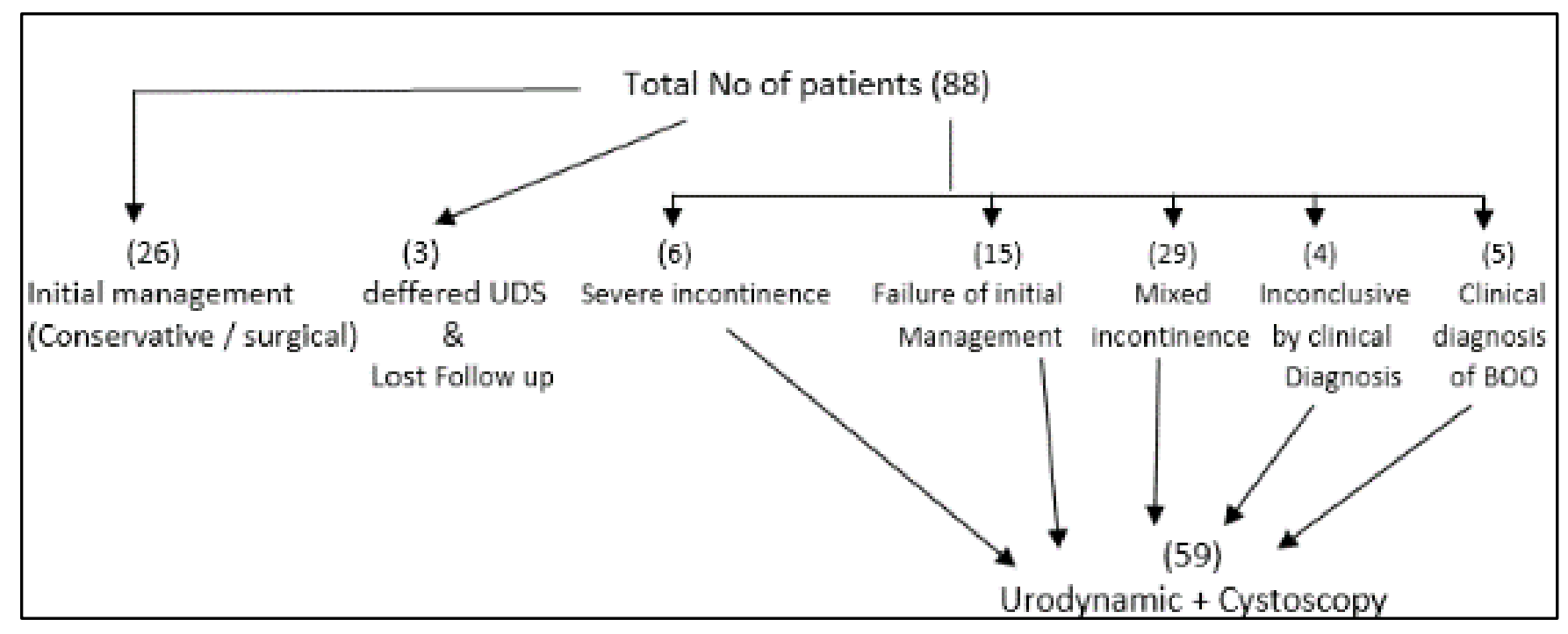

Treated with Initial Conservative/Surgical Management 


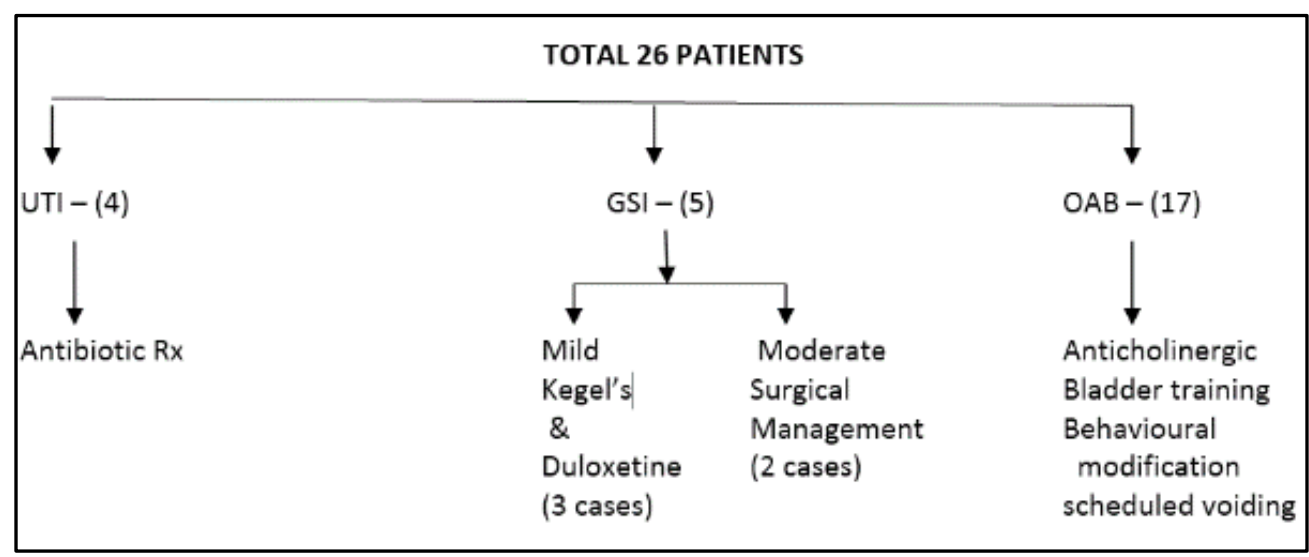

In lines of Sandvik index scoring system, we categorized degree of incontinence and managed. Degree of urinary incontinence

\begin{tabular}{|c|c|c|c|}
\hline \multirow[b]{2}{*}{ Mild } & \multirow[b]{2}{*}{48} & \multicolumn{2}{|c|}{ Medical management } \\
\hline & & 26 & 56 (3 DEFERRED UDS) \\
\hline Modera & 34 & & \\
\hline Severe & 06 & - & 06 \\
\hline
\end{tabular}

Initial conservative management is mandatory before going for UDS in mild and moderate degree of UI.(10) If definite diagnosis of Genuine Stress Incontinence is established by history, appropriate conservative/surgical management can be tried before taking up for UDS.(10,11) UDS is recommended before any decision of surgical correction of urinary incontinence other than GSI and in case of surgical failure, failure of initial management, to investigate mixed, complicated and severe urinary incontinence.(11,12) $32.95 \%$ of the postmenopausal women in our study reported with symptoms of mixed urinary incontinence. This is similar to one large French study, where $49 \%$ reported with mixed urinary incontinence symptoms.(13)

All these postmenopausal women with urinary incontinence were evaluated with thorough history taking utilizing incontinence specific questionnaire, fluid intake/urinary voiding diary for at least 2 days, detailed examination of neurological and urogenital system, Bonney's test for Stress Urinary incontinence. Later diagnostic tests like CUE and URINE C/S and USG TAS/TVS, post-voidal residual urinary volume estimation were done.

\section{Inclusion Criteria}

1. Persistent urinary incontinence even after initial conservative medical management for 3 months.

2. Mixed incontinence.

3. Severe incontinence as per scoring.

4. Failed previous incontinence surgery.

\section{Exclusion Criteria}

1. Cerebrovascular accident.

2. Spinal cord injury/any spinal surgery.

3. Parkinson's disease.

4. Multiple sclerosis.

5. Carcinoma of bladder.

\section{Method and Components of UDS}

Written informed consent was taken from all these patients Methods and units of Multichannel Conventional UDS used in this study maintained the standards recommended by the International Continence Society.(14) Filling and voiding Cystometry was done with the patient in a sitting position.
Bladder was filled at a rate of $50 \mathrm{ml} / \mathrm{min}$. A 6-Fr triple lumen transurethral was inserted into the urethra, a 5-FR rectal balloon catheter was inserted at the anus to measure abdominal, intravesical and detrusor pressures at resting, filling and voiding. Electromyographic electrodes were attached at both sides of anus to measure striated perineal muscle (External) sphincteric activity.

In filling cystometrogram first, strong desire to void, Valsalva leak point pressure, pressure/volume relationship (Compliance), filling volume (Bladder capacity) were noted. During voiding, pressure in the Bladder (Detrusor pressure at Q-max) and urine flow rate while emptying (Pressure-flow studies) were measured.

Then Uroflowmetry was conducted when the patient felt a normal desire to void and rate of urine flow over time (Qmax), urethral pressure profile, time to Q-max, total voiding time, voiding volume were analysed. Later on post-voidal residual urine volume was measured as assessment of bladder emptying.

\section{RESULTS}

The distribution of the patient in our study according to age, parity, BMI, Literacy and mode of delivery were analysed. (Tables-1.2.3.4.5)

\begin{tabular}{|c|c|c|}
\hline Age in Yrs. & No. of Cases & Percentage \\
\hline $45-50$ & 04 & $6.45 \%$ \\
\hline $51-60$ & 24 & $38.70 \%$ \\
\hline $61-70$ & 27 & $43.54 \%$ \\
\hline$>70$ & 7 & $11.29 \%$ \\
\hline \multicolumn{3}{|c|}{ Table 1: Age } \\
\hline
\end{tabular}

Incidence of urinary incontinence increases linearly with age. Increase in severity of UI with age in our study is similar to the pattern seen in the Norwegian study. ${ }^{(15)}$

\begin{tabular}{|c|c|c|}
\hline & No. of Cases & Percentage \\
\hline Nulliparous & 6 & $9.67 \%$ \\
\hline Primipara & 8 & $12.90 \%$ \\
\hline Multipara & 41 & $66.12 \%$ \\
\hline Grand Multipara(> 5) & 7 & $11.29 \%$ \\
\hline \multicolumn{2}{|c|}{ Table 2: Parity } \\
\hline
\end{tabular}


The incidence of urinary incontinence is high in multiparous individuals (66.12\%) than in Nulliparous women $(9.67 \%)$

\begin{tabular}{|c|c|c|}
\hline & No. of Cases & Percentage \\
\hline $22-25$ & 15 & $24.19 \%$ \\
\hline $25-30$ & 23 & $37.09 \%$ \\
\hline $30-35$ & 21 & $33.87 \%$ \\
\hline$>35$ & 03 & $4.83 \%$ \\
\hline \multicolumn{3}{|c|}{ Table 3: BMI } \\
\hline
\end{tabular}

\begin{tabular}{|c|c|c|}
\hline & No. of Cases & Percentage \\
\hline Literate & 48 & $77.41 \%$ \\
\hline Illiterate & 14 & $22.58 \%$ \\
\hline \multicolumn{3}{|c|}{ Table 4 } \\
\hline
\end{tabular}

Most of the patients in our study were educated and belongs to socio economic status class IV

\begin{tabular}{|c|c|c|}
\hline & No. of Cases & Percentage \\
\hline Vaginal & 44 & $70.96 \%$ \\
\hline $\begin{array}{l}\text { Difficult vaginal } \\
\text { forceps/vaccum }\end{array}$ & 04 & $6.45 \%$ \\
\hline Caesarean & 14 & $22.58 \%$ \\
\hline
\end{tabular}

The presence of precipitating factors (One or more), association with cystocele and history of prior surgeries were also recorded (Tables 6,7,8)

\begin{tabular}{|c|c|}
\hline $\begin{array}{c}\text { Chronic Constipation } \\
\text { Chronic Cough }\end{array}$ & 5 \\
\hline Smoking / Alcoholism & 04 \\
\hline Anxiety \& Depression & 12 \\
\hline Medical co-morbidity & 24 \\
\hline Pelvic organ prolapse & 28 \\
\hline \multicolumn{2}{|c|}{ Table 6: Precipitating Factors } \\
\hline
\end{tabular}

Diabetes is the main comorbid condition we observed in our study.(16) Out of 62 patients, prevalence of POP was seen in 28 patients, De Boer and Collega (2010) reported a higher prevalence of $\mathrm{OAB}$ in patients with POP than those without POP.(4) Another study which was done on 4103 women by Lawrence et al 2008 found prevalence of $60 \%$.
Approximately $40 \%$ of patients with POP had describe stress urinary symptoms (Grody 1998).(4)

\begin{tabular}{|c|c|}
\hline Present & $24(38.70 \%)$ \\
Grade I & 9 \\
Grade II & 11 \\
Grade III & 4 \\
\hline Absent & $38(61.30 \%)$ \\
\hline \multicolumn{2}{|c|}{ Table 7: Associated with Cystocele } \\
\hline
\end{tabular}

In our study presence of cystocele with urinary incontinence was observed in $38.7 \%$ of cases which is similar in incidence in the study done by Cardozo and Stanton 1980. More than $40 \%$ of women with UI have a significant cystocele.(4) Enhorning (1961) found that women with mild cystocele had a $20 \%$ incidence of detrusor overactivity and the incidence increases to $52 \%$ in those with moderate-to-severe cystocoele.(4)

\begin{tabular}{|c|c|}
\hline Hysterectomy & 11 \\
Abdominal & 13 \\
Vaginal & 4 \\
Laparoscopic & 1 \\
\hline Previous H/o of Cystocele repair & 27 \\
\hline No Previous H/o surgery & 02 \\
\hline Previous H/o incontinence surgery (TOT) \\
\hline \multicolumn{2}{|c|}{ Table 8: Prior Surgeries } \\
\hline
\end{tabular}

\begin{tabular}{|c|c|c|}
\hline & $\begin{array}{c}\text { No. of } \\
\text { Cases }\end{array}$ & Percentage \\
\hline $\begin{array}{c}\text { Overactive bladder } \\
\text { Mixed (Stress urinary continence } \\
\text { + overactive bladder) }\end{array}$ & 11 & 18.64 \\
\hline Detrusor underactivity & 19 & 25.42 \\
\hline $\begin{array}{c}\text { Detrusor under activity + poor } \\
\text { compliance }\end{array}$ & 3 & 37.28 \\
\hline Normal & 3 & 5.08 \\
\hline Genuine stress incontinence & 2 & 3.38 \\
\hline Bladder outlet obstruction & 3 & 5.08 \\
\hline $\begin{array}{c}\text { DSD (Detrusor sphincter } \\
\text { dyssynergia) }\end{array}$ & 2 & 3.38 \\
\hline $\begin{array}{c}\text { Table 9: (Urodynamic results of 59 patients) } \\
\text { (3 patients deferred urodynamic testing) }\end{array}$ \\
\hline
\end{tabular}

\section{NORMAL}

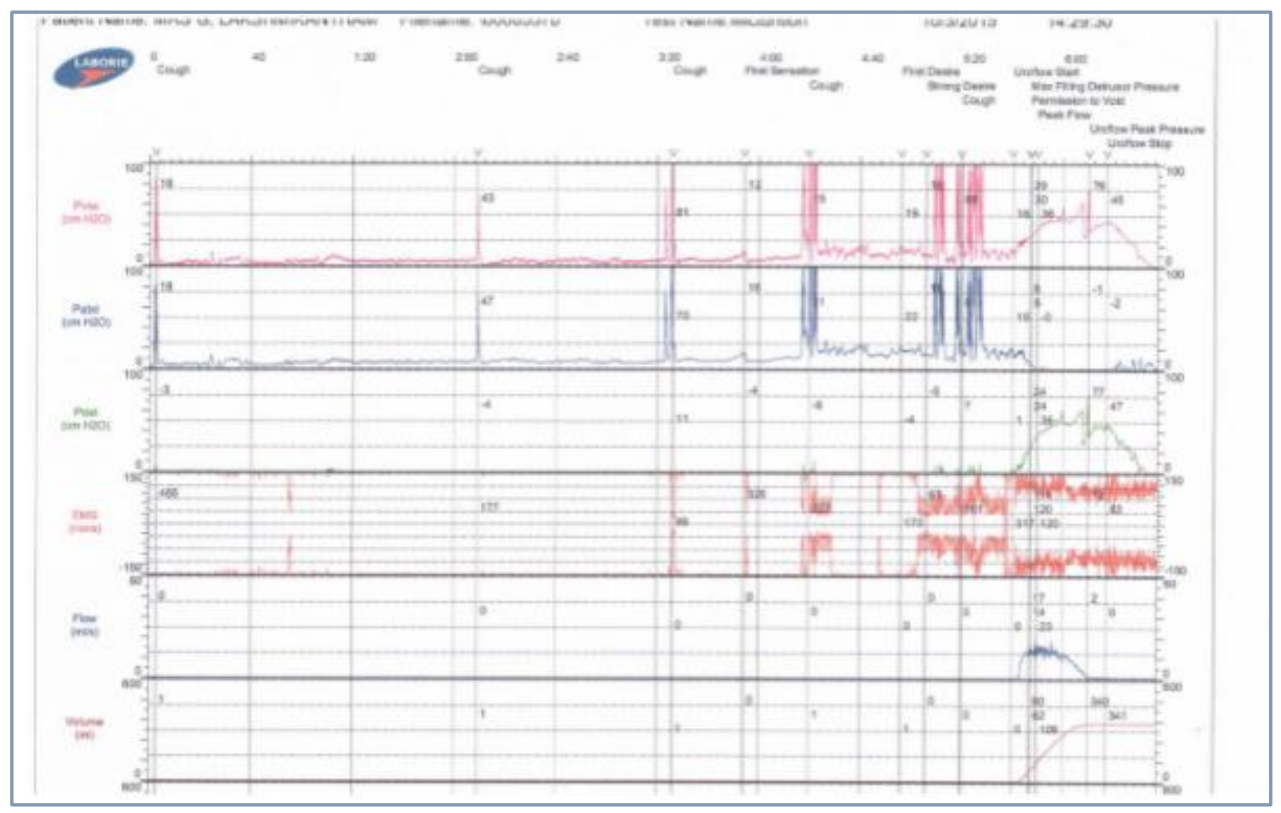




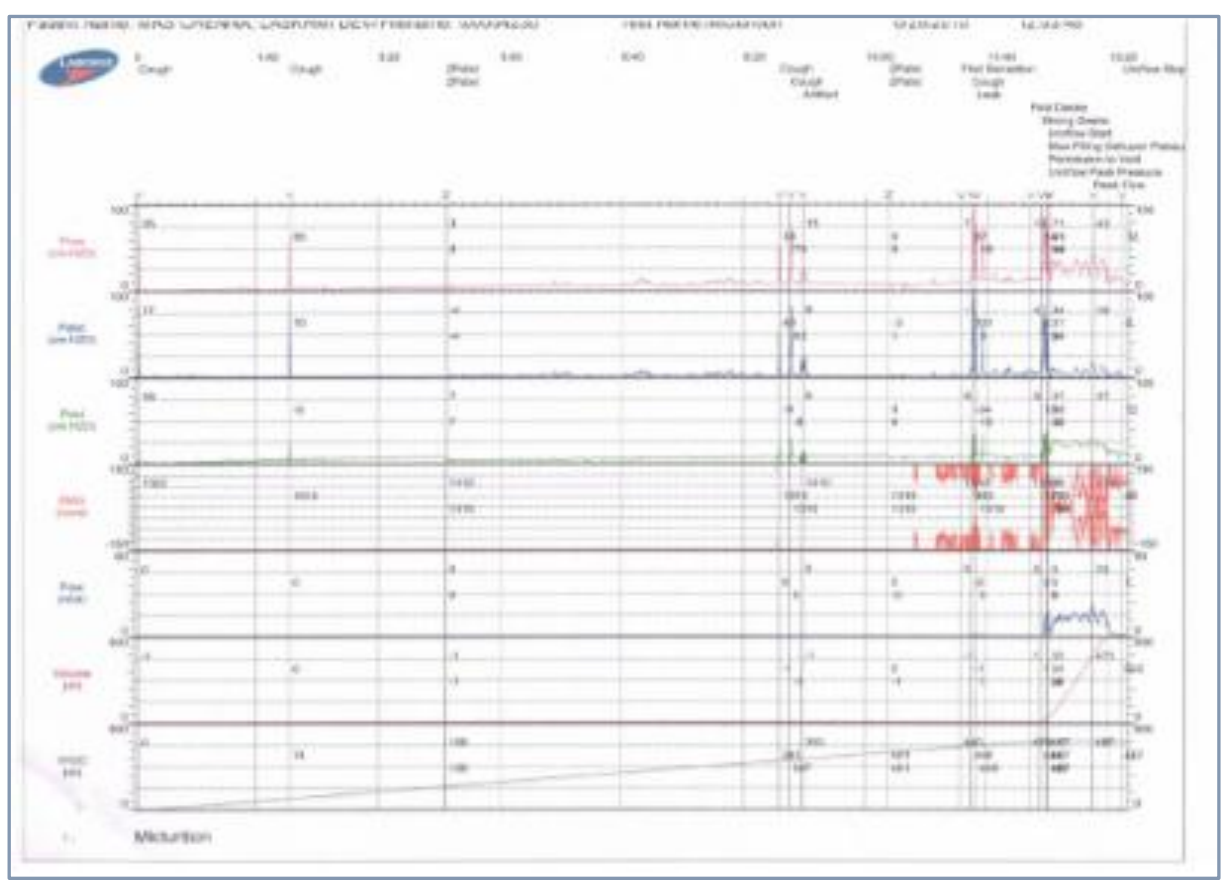

\section{DISCUSSION}

In our study maximum number of incontinence patients are between $61-70$ years of age (43.54\%) and 51-60 years of age $(38.70 \%)$ which is comparable with other studies $(17,18)$.The number of patients reported to OPD after 70 years of age are few. Older women will have worsened voiding function with increase in micturition frequency, nocturnal enuresis, decreased bladder capacity, bladder sensation, bladder contractility and urethral sphincter function. Research has suggested that apoptosis of the rhabdosphincter cells may be one of the primary causes of sphincter dysfunction in older post-menopausal women. The incidence of U.I increases with parity, which is observed in our study $(66.12 \%$ in multi vs. $12.90 \%$ in primi). With each delivery there is $17 \%$ rise in incidence of UI.(17,19)

In our study more number of patients were with BMI 25$30(37.09 \%)$, (33.87\%). Obesity is a single independent factor significantly associated with UI.(17,20) $70.96 \%$ of patients had vaginal delivery, compared to $22.58 \%$ of patients had caesarean delivery in our study with UI. Similar observation is also noted in other studies.
Damage to supporting structures and innervation of the pelvic floor muscles has been implicated in the development of UI following vaginal delivery. $(7,19,21,22)$ Many studies have emphasised the possible protective role of caesarean deliveries.(23)

Past history of hysterectomy with UI in our study is about 28 out of 62 patients. Major studies have shown higher rate of UI in women who underwent hysterectomy and found 33\% incidence of hysterectomy in their studies. $(17,24,25)$ Few studies have not confirmed this association.(26)

Precipitating factors that we observed in our study are presence of Diabetes.(16) anxiety and depression. ${ }^{(17,27,28)}$ and pelvic organ prolapse.

In our study Detrusor underactivity $(37.28 \%)$ was seen in maximum number of patients followed by mixed incontinence $(25.42 \%)$ and $\mathrm{OAB}(18.64 \%)$. Clinical experience and the literature suggest that older women have decreased bladder contractility, increase in $\mathrm{OAB}$ and mixed incontinence and decrease in pure stress symptoms.(29) Our results support this statement.

\section{UNDERACTIVITY}

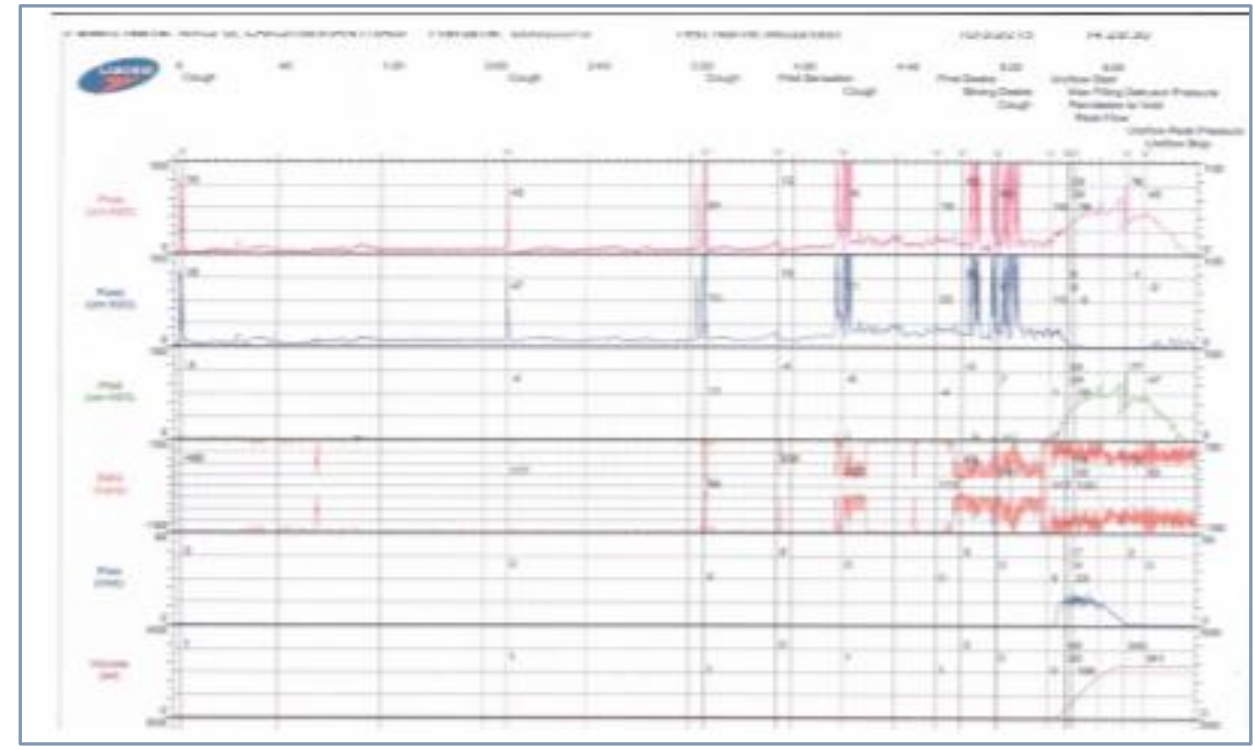


Detrusor underactivity was observed in patients of $\mathrm{OAB}$ who have failed medical management (15 cases).These patients are subjected to UDS and found to have Detrusor underactivity and improved with parasympathomimetics. Detrusor overactivity was seen along with Stress incontinence in 15 patients. In these patients preoperative assessment with UDS enabled us to start anticholinergics which improved surgical success rate. ${ }^{(30)}$
In our study UDS has completely changed the course of management in many cases and guided us to give specific and appropriate treatment.(31) To mention a few cases. Two patients were referred to us with features of Genuine Stress incontinence and after evaluation with UDS, they were found to have $\mathrm{OAB}$ and treated accordingly and avoided surgery.

OAB

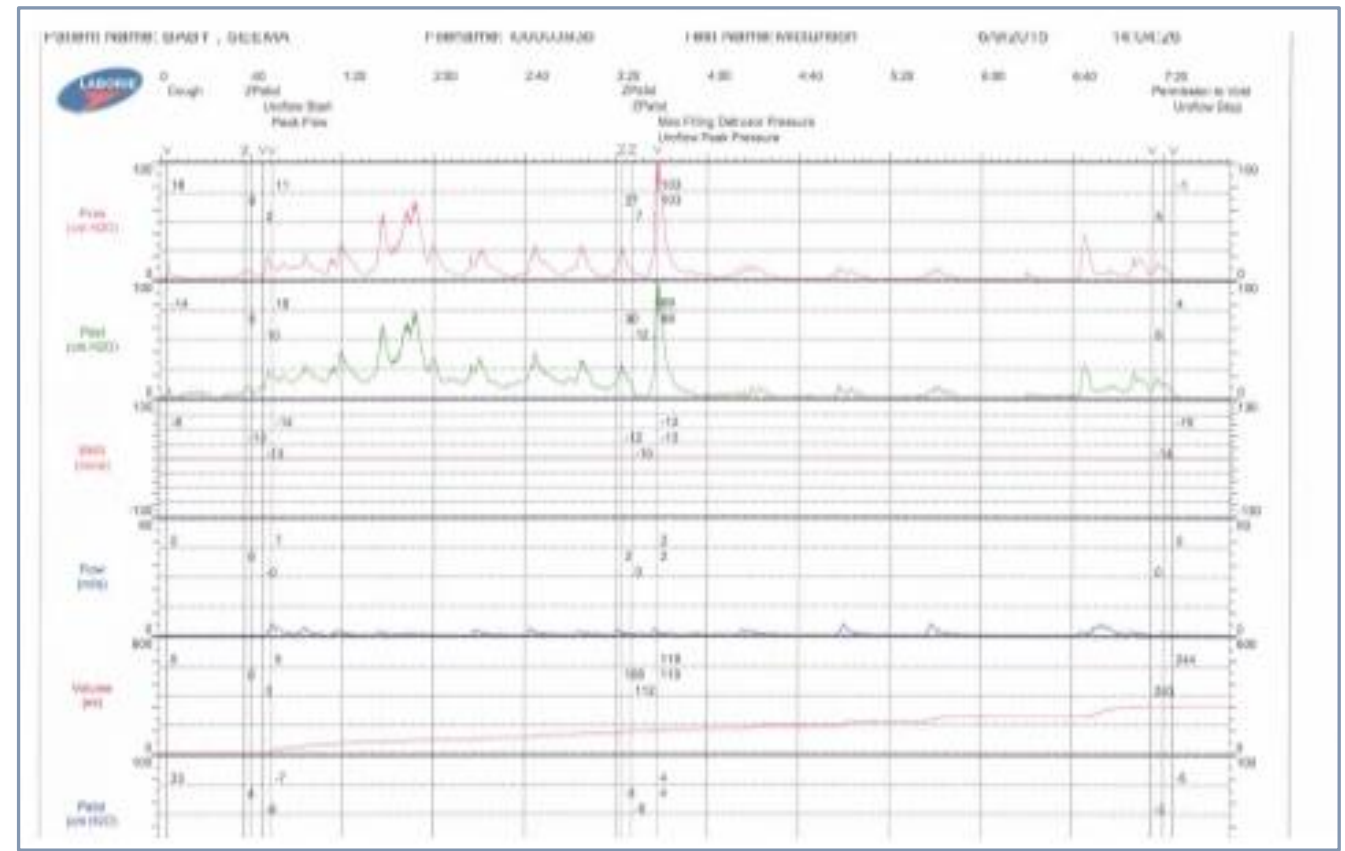

With clinical diagnosis of BOO, two post-hysterectomy patients have underwent repeated urethral dilatation before referral to us. After UDS they were found to have DSD and treated with anticholinergics and Alpha blockers.

\section{Detrusor Sphincter Dyssynergia (DSD)}

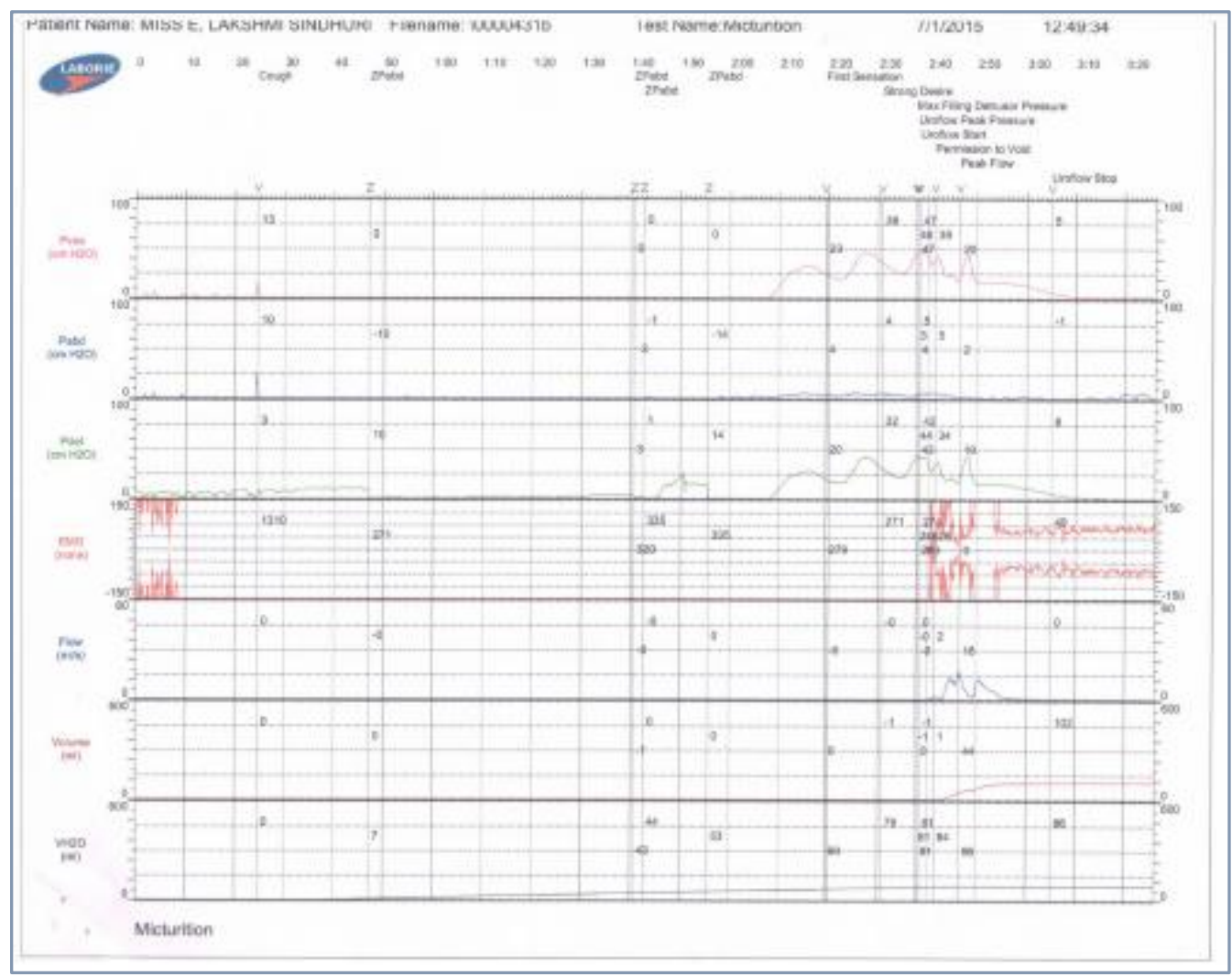


One patient with clinical diagnosis of severe stress UI, planned for TOT and on evaluation with UDS had Detrusor underactivity with continuous urinary leakage due to severs intrinsic sphincter deficiency. Her symptoms controlled with cholinergics and Duloxetine and subjected to suburethral injection of bulking agents.

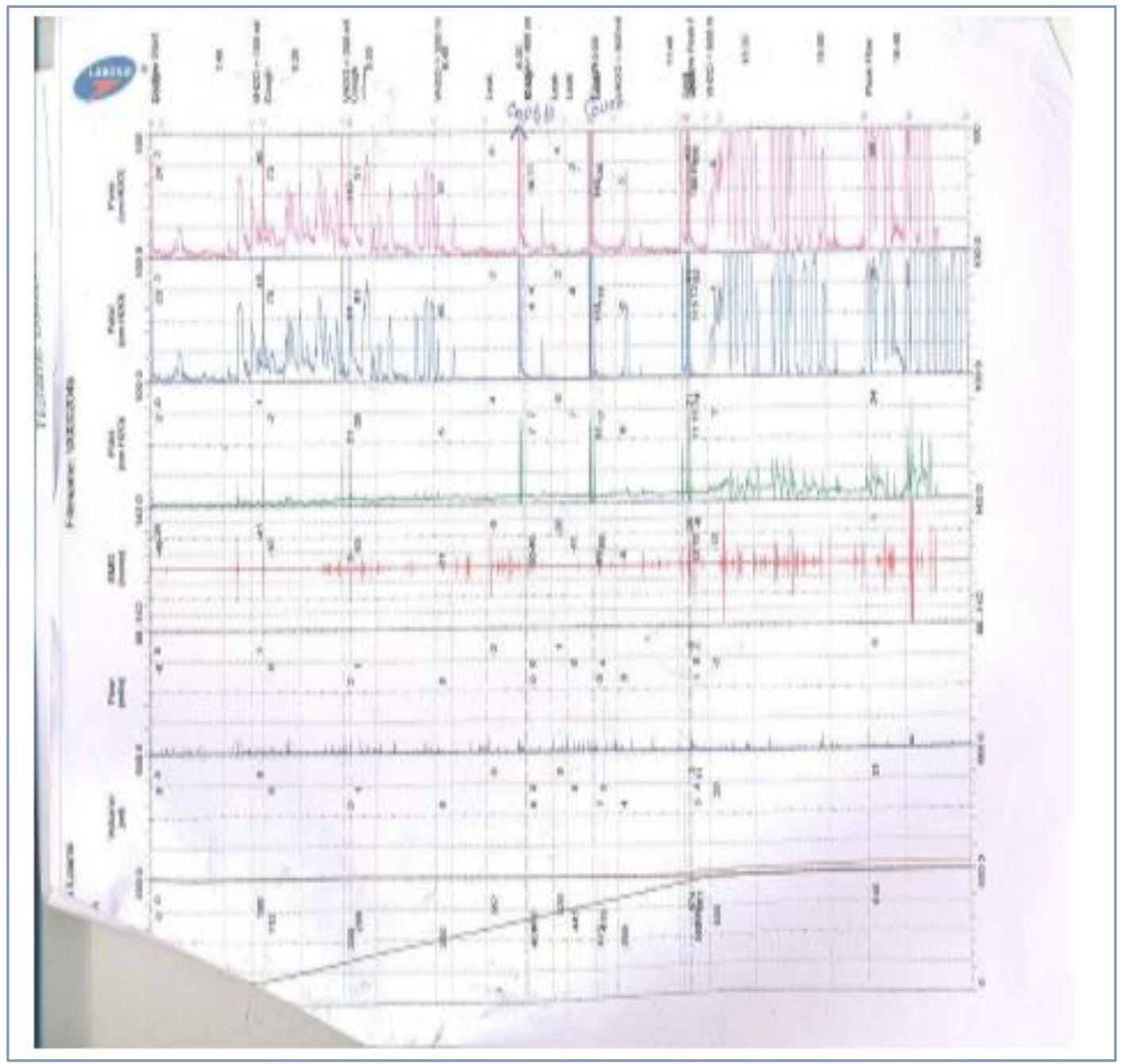

Fig: Severe Intrinsic Sphincter deficiency with detrusor underactivity

Established voiding and continent centres have advised that these patients should thoroughly evaluated with UDS and their treatment should be individualized according to their symptoms with team approach. $(30,31)$

\section{CONCLUSION}

Urodynamic study is a gold standard in evaluation of urinary incontinence which guide us for specific management with better results. UDS provide enough information for treatment decision and prognosis in cases of UI. Research is critically needed to provide data that will allow better understanding of the unique nature of this urologic disease in these older postmenopausal women.

\section{REFERENCES}

1. Patrick DL, Martin ML, Bushnell DM, Yalcin I, Wagner TH, Buesching DP. Quality of life of women with urinary incontinence: further development of the Incontinence Quality of Life Instrument (I-QOL). Urology 1999;537176.

2. Urodynamic diagnosis and Quality of Life in women presenting for evaluation of Urinary Incontinence; Australian and New Zealand, Journal of Obst and Gynaec 20q11; Oct 5 (416-420), Duggan P.

3. Wagner TH, Hu TW. Economic costs of urinary incontinence in 1995. Urology 1998;51:355-361.
4. Campbell-Walsh, Urology (10 $10^{\text {th }}$ edition, volume-3, Wein Kavoussi, Novick, Partin, Petars, Page-1873-1885).

5. Sandvik H, Hunskaar S, Seim A, Hermstad R, Vanvik A, Bratt $\mathrm{H}$. Validation of a severity index in female urinary incontinence and its implementation in an epidemiological survey. J Epidemiol Community Health 1993;47:497-499.

6. Hanley J, Capewell A, Hagen S. Validity study of the Severity Index, a simple measure of urinary incontinence in women. BMJ 2001;322:1096-1097.

7. Sandvik H, Seim A, Vanvik A, et al. Severity index for epidemiological surveys of female urinary incontinence: comparison with 48-hour pad-weighing tests. Neurourol Urodyn 2000;19:137-145.

8. Robertson, Neal, 1998, Robertson A, Neal De: Ambulatory urodynamics; In: Nitti VW, ed, Practical urodynamics, Philadelphia, WB Sandure, 1998;273-286.

9. Comparison of ambulatory versus Conventional Urodynamics in females with urinary incontinence. Neurourol Urodyn 2010; April 29(4):519-21, Dokmeci F', Seval M, Gok H. 
10. Evaluation of female urinary incontinence; Urol Clinical North America 1991; Synder LA, Lipsitz Du (197-209).

11. Systematic review and evaluation of methods of assessing Urinary Incontinence. Health Technol Asen, 2006; Feb 10(6):1-132, Martin JL' Williams KS, Abram KR, Turner DA.

12. Urodynamic examination in the investigation of nonneurological female urinary incontinence; J Gynecol Obstet Biol Reprod (Paris) 2003, Dec; Domperye P, Pizzoferrato AC.

13. Recommendations for Urodynamic examination in the investigation of non-neurological female urinary incontinence; Pro urol. 2007; Nov 17(6suppl2):1264-84, Article in French, Hamier JF.

14. Abrams, et al. The standardisation of terminology of Lower Urinary Tract Function; report from the Standardisation Sub-committee of the International Continence Society. Neurourol Urodynamics, 2002(2):p:167-168.

15. Hannestad YS, Rortveit G, Sandvik H, et al. Epidemiology of Incontinence in the County of Nord-Trondelag: a community-based epidemiological survey of female urinary incontinence: the Norwegian Epincont study: Epidemiology of Incontinence in the County of NordTrondelag. J Clin Epidemiol 2000;53:1150-1157.

16. Ho C, Tai HC, Yu HJ (2010). Urodynamic findings in female diabetic patients with and without overactive bladder symptoms, Neurourol, Urodyn 29.

17. Urinary incontinence in US women. A population based study. Jennifer L; Melville, MD, MPH. Arch Intern Med 2005:165(50):537-542.

18. Brown JS, Seeley DG, Fong J, Black DM, Ensrud KE, Grady D. Urinary incontinence in older women: who is at risk? Study of Osteoporotic Fractures Research Group. Obstet Gynecol 1996;87:715-721.

19. Foldspang A, Mommsen S, Lam GW, et al. Parity as a correlate of adult female urinary incontinence prevalence. J Epidemiol Community Health 1992;46:595-600.

20. Bortolotti A, Bernardini B, Colli E, et al. Prevalence and risk factors for urinary incontinence in Italy. Eur Urol 2000;37:30-35.
21. Grodstein F, Fretts R, Lifford K, et al. Association of age, race and obstetric history with urinary symptoms among women in the Nurses' Health Study. Am J Obstet Gynecol 2003;189:428-434.

22. Thom DH, Van den E, Eden SK, et al. Evaluation of parturition and other reproductive variables as risk factors for urinary incontinence in later life. Obstet Gynecol 1997;90:983-989.

23. Milsom I, Ekelund P, Molander U, et al. The influence of age, parity, oral contraception, hysterectomy and menopause on the prevalence of urinary incontinence in women. J Urol 1993;149:1459-1462.

24. Farghaly SA, Hindmarsh JR, Worth PH. Posthysterectomy urethral dysfunction: evaluation and management. Br J Urol 1986;58:299-302.

25. Van der Vaart CH, Van der Bom JG, de Leeuw JR, et al. The contribution of hysterectomy to the occurrence of urge and stress urinary incontinence symptoms. BJOG 2002;109:149-154.

26. Mommsen S, Foldspang A, Elving L, et al. Association between urinary incontinence in women and a previous history of surgery. Br J Urol 1993;72:30-37.

27. Melville JL, Walker E, Katon W, Lentz G, Miller J, Fenner D. Prevalence of comorbid psychiatric illness and its impact on symptom perception, quality of life and functional status in women with urinary incontinence. Am J Obstet Gynecol 2002;187:80-87.

28. Stach-Lempinen B, Hakala AL, Laippala P, Lehtinen K, Metsanoja R, Kujansuu E. Severe depression determines quality of life in urinary incontinent women. Neurourol Urodyn 2003;22:563-568.

29. Scarpero HM, Kaufman MR, Koski M, et al. Urodynamics best practices: American urological association update series 2009, Lesson 9.

30. Long-Yau Lin, Nan-Hungyeh, Ching-Yihin. Comparison of Urodynamic characteristics between female patients with Overactive Bladder and $\mathrm{OAB}+$ Stress Urinary Incontinence; (UrolGyn Nov 2004), Volume 64, Issue 5, Page 945-949.

31. McNanley AR, Duecy EE, Buchsbaum GM. Symptombased, clinical and urodynamic diagnosis of Urinary Incontinence: how well do they correlate in Postmenopausal women. Female Pelvic Med Reconstr Surg. 2010 Mar;16(2):97-101. 